\title{
Pareto, Mosca e a metodologia de uma nova ciência política
}

Pareto, Mosca and the methodology of a new political science

Os processos de institucionalização da ciência política como uma disciplina acadêmica foram acompanhados, em diferentes contextos nacionais, por uma defesa do caráter científico do empreendimento. Assim, ao mesmo tempo que um objeto autônomo do conhecimento era apresentado - a política -, também era afirmado um método científico apropriado. Frequentemente esse método foi identificado com aquele predominante nas ciências naturais, que serviam como modelo de cientificidade para a nascente disciplina.

Essa reivindicação do primado metodológico das ciências naturais manifestou-se ao longo de toda a história da ciência política e não deixa, ainda hoje, de se fazer ouvir. Apesar da crítica ao positivismo que se desenvolveu intensamente na ciência política a partir do final dos anos 1960 e da denúncia que as correntes antifundacionalistas fizeram das tentativas de explicar o mundo real por meio da observação empírica, as últimas décadas presenciaram uma forte expansão de métodos experimentais tomados de empréstimo das ciências naturais e aplicados ao estudo dos fenômenos políticos. Antes de 1975 apenas cinco artigos publicados na American Political Science Review haviam usado métodos experimentais; já entre 1975 e 1990 foram dezesseis estudos desse tipo. A partir daí o número sofreu um crescimento exponencial. Em 103 anos de existência da revista, mais da metade dos artigos cujos resultados se baseavam em algum tipo de experimentação foram publicados após 1992 (Druckman et al., 2011, p. 5).

É professor do Departamento de Ciência Política da Universidade Estadual de Campinas (Unicamp). E-mail: albianchi@terra.com.br. 
Ao longo dessa história, entretanto, o significado atribuído à noção de experimentação na ciência política nem sempre foi o mesmo, assim como nem sempre foi igual a própria ideia de política que dá nome à disciplina. Reconstruir historicamente essa diversidade pode ajudar a reconhecer as alternativas teóricas e metodológicas que existiram em diferentes momentos e a conformar uma visão menos unilateral e homogênea da trajetória da ciência política. Este artigo descreve um momento da história da formação da ciência política na Itália, no final do século XIX e início do século XX, expondo as concepções teóricas de dois de seus expoentes - Gaetano Mosca (1858-1941) e Vilfredo Pareto (1848-1923). Pretende-se com isso contribuir para a constituição dessa visão mais nuançada da história da ciência política e a uma desnaturalização das ideias de método e experimento no campo disciplinar.

A escolha dos autores merece rápida justificativa. As pesquisas de Gaetano Mosca e Vilfredo Pareto costumam ser destacadas como pontos chaves da afirmação de uma ciência política italiana (cf. Bobbio, 2002; Sola, 1990, 1994). Com frequência esses autores são tratados como se formassem uma escola perfeitamente homogênea de pensamento, a qual muitas vezes é chamada de "escola italiana" (cf. por exemplo Graziano, 1987a). Os percursos intelectuais de ambos são, entretanto, muito diferentes, e os resultados de suas pesquisas nem sempre convergem. Mosca começou sua carreira acadêmica no âmbito dos estudos jurídicos e chegou, por meio do método histórico, ao estudo da classe política e do pensamento político. Pareto, por sua vez, iniciou sua vida como engenheiro para mais tarde contribuir de modo decisivo para a renovação da economia política, concluindo, por meio do método lógico-experimental, com a exposição de uma abrangente teoria sociológica geral.

Politicamente esses autores também percorreram caminhos de sentido inverso. Mosca considerava-se inicialmente um herdeiro da Destra Storica, o grupo dirigente que comandou a unificação italiana e expôs em suas primeiras obras uma aguda crítica, quando não uma simples recusa, da democracia parlamentar. Já nos últimos anos do século XIX essa crítica tornou-se mais matizada, e Mosca, embora permanecesse "un conservatore galantuomo", como foi chamado certa vez por Piero Gobbeti, e um adversário do sufrágio universal, dos sindicatos e do socialismo, passou a identificar-se cada vez mais com o liberalismo italiano e, mais tarde, tornou-se opositor do governo de Benito Mussolini (1883-1945). Pareto, por sua vez, começou como um 
liberal radical e chegou a nutrir certa simpatia pelos socialistas, vendo-os como aliados na luta pela liberdade e pela renovação da Itália. Mas no início do novecentos, o professor de Lausanne assumiu uma atitude cada vez mais cética para com as elites italianas e os socialistas, o que tornou sua crítica à democracia liberal cada vez mais acre até que, no final de sua vida, depositou suas esperanças no advento do regime mussoliniano.

Trajetórias tão diversas não impediram esses autores de partilhar um objetivo comum: a busca daquilo que consideravam ser um conhecimento verdadeiramente científico dos fenômenos políticos. O que permite reconhecer esses autores como os fundadores da moderna ciência política italiana é sua procura incessante de um conhecimento científico da política que fosse construído de acordo com parâmetros de rigor que poderiam ser assemelhados às ciências naturais ou, pelo menos, àquela que ambos consideravam ser a ciência social mais desenvolvida da época, a nova economia política de inspiração marginalista (Mosca, 1982b, p. 552; Pareto, 1980, p. 133).

O método que orienta a investigação aqui exposta é o de uma história política do pensamento político. Nessa perspectiva entende-se que todo pensamento político deve ser concebido como um movimento na luta política dos partidos. Se o pensamento político é um movimento na luta política, a história desse pensamento não pode deixar de ser, ela própria, política. Daí a importância de reconstruir os contextos políticos e intelectuais nos quais as ideias políticas encontram seu lugar. As duas primeiras seções deste artigo exploram as ideias de Mosca e Pareto, enfatizando as concepções de ciência e de método científico que cada um deles abraçava. Em uma terceira seção discutem-se os limites de suas noções de experimento, experiência e observação, as quais apresentavam grande ambiguidade e frequentemente se confundiam. Uma última e conclusiva seção prospecta algumas consequências relevantes das ideias desses autores para compreendermos os desafios da ciência política contemporânea.

\section{Gaetano Mosca e a fundação da ciência política contemporânea}

Apesar de vida breve e atribulada, as diversas iniciativas que no final do século XIX pretenderam organizar os estudos políticos na universidade italiana serviram para estimular novas investigações ${ }^{1}$. Muitos jovens promis-

1 Desde o início do século XVII é possível notar iniciativas com vistas à constituição de uma academia voltada para o estudo do governo, como na obra do sacerdote modenese Antonio Muratori (1672- 
sores passaram pelo corso complementare di scienze economico-administrative criado na Università di Roma, em 1879, destacando-se entre eles Gaetano Mosca. O jovem Mosca havia obtido a láurea em jurisprudência em Palermo, sua cidade natal, e em 1882 inscreveu-se na Facoltà Giuridica dell'Università di Roma para complementar sua formação. No corso frequentou disciplinas de estatística, economia política, história e comparação das constituições modernas, tomou contato com destacados professores, acompanhou diretamente os debates acadêmicos e as discussões parlamentares. Enfim, foi em Roma que completou sua formação e se aproximou da cultura cosmopolita da época, experiência que julgou necessário registrar na introdução de $T e$ orica dei governi e governi parlamentare, de 1883: "No curso complementar de ciência política e administrativa de Roma, que também frequentei, tive grande ajuda com livros e encorajamento do egrégio prof. Protonotari, ajuda e conselhos também do prof. Palma, e me beneficiei muito da visão clara, límpida e superior que em todos os argumentos das ciências sociais são próprias do prof. Messedaglia" (Mosca, 1982a, p. 192)².

Quando Mosca frequentou o curso especial, a situação política italiana era muito diferente daquela de 1875, ano em que o ministro Bonghi criou o primeiro corso speciale para o estudo das scienze politiche. Em 1876, uma crise parlamentar levou à queda da Destra Storica e conduziu a Sinistra, liderada por Agostino Depretis (1813-1887), ao poder. A opinião pública da época considerou o episódio uma "revolução parlamentar" e uma oportunidade para a renovação da vida política italiana. A unificação nacional havia sido concluída cinco anos antes, mas seu resultado estava muito distante daquele imaginado. A distância entre o parlamento, sede do país legal, e o povo, o

1750). Mas foi após a Revolução Francesa que essas iniciativas se tornaram mais consistentes, como nas scuole speciali politico-legali, que Giandomenico Romagnosi (1761-1835) promoveu e organizou em Milão. À medida que o movimento de independência e unificação política da península ganhava força, fortaleceu-se a ideia de que seria necessário criar escolas que tivessem por objetivo formar os grupos políticos dirigentes. Várias iniciativas tiveram lugar após a constituição do novo Reino da Itália, como a criação da Facoltà Politico-Administrativa, em 1862. Mas foi apenas em 1924, já sob o fascismo, que foi criada a primeira Scuola di Sicenze Politiche na Università di Roma. Sobre a história do pensamento e da ciência política italiana na primeira metade do século XX, ver, entre outros Albertoni (1985), Bedeschi (2002), Bobbio (2002), Palano (2005), Perticone (1950) e Sola (1990).

2 Todas as traduções dos originais são do autor do artigo. Note-se que Mosca se refere a um curso de scienze politiche. É muito comum os comentadores se equivocarem a respeito da denominação do curso. Sola (1982, p. 83), por exemplo, afirma que Mosca se matriculou na Scuola Economico-Amministrativa, a qual nunca chegou efetivamente a funcionar. Outros referem-se a um corso complementare politico-amministrativo, ou mesmo "di scienze politica", que nunca existiram. As frequentes mudanças da nomenclatura, mas principalmente o caráter ambíguo do curso justificam esses pequenos equívocos. 
país real, era gigantesca, e a insatisfação daqueles que não encontravam nos deputados e senadores sua representação cada vez maior.

A queda da Destra e o advento da Sinistra simbolizavam uma perspectiva de transformação social e de expansão da base política do Estado por meio de uma reforma eleitoral. Operários do Norte, trabalhadores rurais do Sul e pequenos funcionários das grandes cidades; socialistas, republicanos, liberais radicais e católicos; enfim, não foram poucos os que viram na ascensão de Depretis o advento de uma nova era na política italiana e a realização das esperanças despertadas pela unificação (Cammarano, 1999, p. 115-39). Esse sonho rapidamente se esvaneceu. Protagonizando um acordo parlamentar com elementos da Destra, Depretis inaugurou o trasformismo na política italiana, reproduzindo de maneira ampliada a política de compromissos e clientelismo característica do novo reino ${ }^{3}$.

Não foi necessário muito tempo para que as mentes mais clarividentes da política percebessem o advento de uma crise do parlamentarismo. Não se tratava mais da crise de um ou outro gabinete ministerial, da sucessão de chefes de governo ou mesmo da alternância dos partidos. O que os mais lúcidos passaram a ver foram os limites da instituição parlamentar na Itália e a sua incapacidade de expressar os reais interesses da nação. Em suma, enxergam a evidente contradição entre a mesquinha prática política na qual imperavam os interesses particularistas, a troca de favores e os ganhos imediatos, e a promessa liberal de um parlamento que expressasse o interesse geral (Cammarano, 1999, p. 41). A expansão da base eleitoral com a reforma de 1882 tornou o problema ainda mais agudo. Para aqueles mais conservadores, como o jovem Gaetano Mosca, era o encontro de uma estreita classe dirigente com o "despotismo das massas", o momento no qual a contradição tornou-se explosiva dando origem à crise da democracia parlamentar.

Foi a aguda percepção dessa crise o que levou o estudante Mosca a escrever freneticamente sua obra Teorica dei governi e governo parlamentare, ainda

3 Antonio Gramsci explicou o trasformismo no artigo "Il regime dei pascià", publicado no jornal Avanti!, em julho de 1918:"Itália é um país onde sempre se verifica este fenômeno curioso: os homens políticos, chegando ao poder, têm imediatamente renegado as ideias e os programas de ação que propugnaram como simples cidadãos" (Gramsci, 1984, p. 217). A expressão trasformismo foi sugerida pelo próprio Depretis em seu famoso discurso de 8 de outubro de 1882. Respondendo àqueles que o acusavam de pactuar com a Destra, afirmou: "Se alguém deseja entrar em nossas fileiras, se deseja aceitar meu modesto programa, se deseja transformar-se e tornar-se progressista, como posso eu rejeitá-lo?" (apud Candeloro, 1970, p. 161). 
durante o período em que frequentava as aulas do corso complementare. $\mathrm{O}$ livro iniciava-se de modo polêmico, com o autor recusando a classificação aristotélica das diferentes formas de governo de acordo com o número de governantes - democráticos, aristocráticos e monárquicos. A essa classificação Mosca opôs a máxima que organizou sua reflexão ao longo das décadas seguintes:

Em todas as sociedades regularmente constituídas, nas quais há aquilo que se denomina um governo, nós, em vez de ver que a autoridade deste se exerce em nome do universo do povo, ou de uma aristocracia dominante, ou de um único soberano [...], encontramos, constantíssimo, outro fato: que os governantes, ou seja, aqueles que têm em suas mãos e exercem o público poder, são sempre uma minoria, e que abaixo destes há uma classe de pessoas que nunca participam realmente de algum modo do governo, e não fazem senão subi-lo; esses podem ser chamados de os governados (Mosca, 1982a, p. 203).

A partir desse fato constante, Mosca construiu seu argumento: a "massa, a maioria" tomaria parte da política apenas como um meio que permitiria aos governantes exercer seu poder. Frequentemente essa participação não seria sequer consciente ou voluntária, seja porque a maioria não reconheceria a utilidade dela, seja porque seria coagida a agir, seja porque se submeteria passivamente a ação política dos governantes (Mosca, 1982a, p. 206). O programa de pesquisa mosquiano reverberava assim influencias maquiavelianas. Para o autor de Il principe, a conquista e a manutenção do poder político encontravam-se no centro de sua reflexão. Mosca não estava longe dessa impostação quando mobilizou suas forças para estudar como a classe política exercia seu poder, ou seja, como, apesar de ser uma pequena minoria, conseguia sobrepor-se ao grande número e subordiná-lo.

Afirmando que tudo aquilo que no governo seria parte ativa e exercício de autoridade recairia sempre sob a responsabilidade de uma classe especial de pessoas, Mosca anunciou a existência daquilo que denominou de "classe política" (Mosca, 1982a, p. 207)4. A força e a eficácia dessa classe dependeriam da força e da eficácia da máquina governativa. Quando esta tivesse um grau elevado de aperfeiçoamento, seria possível que os governantes, de modo or-

4 De acordo com a situação, Gaetano Mosca também utilizava os sinônimos de "classe governante", "classe dirigente", "classe dominante", "classes superiores", "classes elevadas", "governantes", "elementos dominadores" e"minoria organizada" (cf. a observação de Giorgio Sola em Mosca, 1982a, p. 207n). 
ganizado e disciplinado, absorvessem os recursos econômicos e políticos da sociedade utilizando-os em proveito próprio. Mas, quando essa máquina não estivesse senão esboçada, cada um dos indivíduos da classe governante agiria sem coordenação, e prevaleceriam a violência privada e o poder pessoal do homem sobre o homem (Mosca, 1982a, p. 212). Como tornar a dominação da classe política efetiva, estável e adequada ao desenvolvimento da nação? Esse era o problema que agitava a imaginação de Mosca.

O implícito reencontro com Machiavelli permitiu a Mosca afastar-se tanto do âmbito dos estudos jurídicos como da investigação filosófica. A Teorica, mais do que fundar um novo campo de investigação, reencontrou uma tradição de estudos políticos que estava adormecida na Itália, mas que após o Risorgimento começava lentamente a despertar. Mosca, entretanto, recusava a ideia de que Machiavelli tivesse "sido o fundador de uma verdadeira ciência política”, uma vez que faltariam ao florentino os conhecimentos que apenas o desenvolvimento da crítica histórica teriam permitido (Mosca e Bouthoul, 1958, p. 115). Mas se Machiavelli não poderia, segundo o autor da Teorica, ser reconhecido como o fundador da ciência política, ele não deixava de ter méritos, uma vez que foi capaz de ver "que em todas as sociedades humanas existem tendências políticas constantes e que estas podem ser encontradas estudando-se a história dos diferentes povos" (Mosca e Bouthoul, 1958, p. 116). Estabelecer as regularidades históricas por meio da análise histórica comparada era o projeto teórico do próprio Mosca.

Já na Teorica esse método histórico e comparativo da pesquisa política encontrava seu lugar. A "observação dos fatos" deveria ser o ponto de partida de toda investigação. Em seu Proemio, de 1883, Mosca narrou como procurou conversar com "toda sorte de pessoas, homens da assim chamada boa sociedade, empregados, magistrados, oficiais, deputados, operários, camponeses", e afirmou ter procurado observar o lugar que cada uma dessas pessoas tinha na vida pública e sempre que encontrou uma opinião sobre a política anotou e recolheu com cuidado, "seja aquela de meu sapateiro ou de sua Excelência, o ministro" (Mosca, 1982a, p. 189).

Mosca mostrou-se constrangido com a ingenuidade juvenil do Proemio em sua "Prefazione alla seconda edizione", escrita em 1924, embora em sua defesa possa ser dito que os exageros que ali tinham sede não compareciam no texto principal da Teorica (cf. Mosca, 1982a, p. 194). De fato, na rapidíssima exposição que nele fez do método de pesquisa não há referência a sua 
observação ou experiência pessoal, e em sua pesquisa o sujeito da investigação não aparecia. Esse sujeito oculto permitia enfatizar o caráter coletivo da observação e da experiência, cujos achados eram sempre apresentados na obra como fatos que poderiam ser percebidos e corroborados por outros indivíduos.

Assim como muitos outros, o autor utilizou as palavras iniciais de seu texto para lamentar o atraso das ciências sociais com relação às ciências naturais, partilhando uma observação e uma experiência sobre a própria prática científica. Evidenciando uma clara inspiração na obra de Auguste Comte, Mosca suspirou: a "física, a química, a astronomia, a geografia, a geologia, a botânica, [...] já adquiriram caráter rigorosamente científico", mas nas "ciências sociais [...] não se encontram ainda aqueles princípios gerais cientificamente provados", o que condenava estas a uma situação de inferioridade perante as primeiras (Mosca, 1982a, p. 198-9).

Tal inferioridade faria com que nas ciências sociais os princípios que poderiam organizar um conhecimento efetivo permanecessem sempre na condição de hipóteses discutíveis ou questionáveis até mesmo pelo conhecimento vulgar dos diletantes. As ciências naturais avançariam mais rapidamente porque necessitariam de um menor número de observações para comprovar suas teses, obteriam essas observações de modo mais fácil e poderiam adquiri-las livremente, pois já teriam se libertado dos preconceitos e dos juízos a priori característicos da religião e do sentimentalismo. Nada disso seria possível nas ciências sociais, em que seria necessário um maior número de observações para comprovar uma tese, e estas exigiriam um vasto conhecimento histórico e uma seleção acurada do material a ser estudado, conhecimento que para o autor da Teorica estaria sempre embotado pelos velhos hábitos intelectuais pré-científicos e pelo sentimentalismo (Mosca, 1982a, p. 199-201).

Na metodologia apresentada por Mosca a noção de experiência ocupava um lugar central e era análoga a noção de experimento nas ciências naturais. Para o jovem cientista, nas ciências sociais "toda a observação deve estar baseada sobre a experiência, isto é, sobre o estudo dos fenômenos como naturalmente se desenvolvem e nas condições nas quais se apresentam" (Mosca, 1982a, p. 199). Mas essa experiência não diria respeito apenas às coisas vividas no presente. Tratar-se-ia, antes de mais nada, de uma "experiência secular" do desenvolvimento das sociedades humanas que permitiria 
distinguir os fatos relevantes daqueles irrelevantes: "É necessário, em suma, que o estudioso tenha sob o olhar uma verdadeira e própria história das várias sociedades humanas e que seriamente a aprofunde" (Mosca, 1982a, p. 200).

O empreendimento proposto era colossal. Não apenas ele implicava certa etnografia da vida política, a exemplo daquela descrita por Mosca no Proemio, como exigia um profundo conhecimento da história. Não há como deixar de recordar a máxima de Machiavelli em Il principe, na qual afirmava não ter encontrado nada melhor dentre suas posses para ofertar "do que o conhecimento das ações dos grandes homens que aprendi através de uma longa experiência das coisas modernas e um contínuo estudo das antigas" (Machiavelli, 1971, p. 257). Era assim, na experiência do presente e do passado, que o autor da Teorica pretendia sustentar maquiavelianamente sua investigação. As dificuldades eram enormes, mas o jovem Mosca se mostrava otimista: "Apesar disso [desses limites] acreditamos firmemente que uma verdadeira ciência social, embora ainda não exista, pode deste momento em diante começar a existir; se até o declinar do século XIX não nasceu, não é impossível materialmente que no fim do século, antes que ele termine, não possa nascer" (Mosca, 1982a, p. 201).

Esse programa de investigação foi refinado, e não abandonado, em sua obra posterior Elementi di scienza politica, de 1896. As tendências fortemente conservadoras da Teorica começavam a ser matizadas pelo autor, o que ficou ainda mais nítido na segunda edição dos Elementi, de 1922, e na terceira, de 1933, mas as linhas gerais da investigação continuavam as mesmas. Mosca iniciou sua nova obra definindo a ciência que dava nome a sua obra como o estudo das "tendências psicológicas constantes que determinam a ação das massas humanas" (Mosca, 1982b, p. 549). O estudo dessas tendências poderia remontar a Aristóteles que, com sua Política, tratara de investigá-las e avançara até mesmo na definição de uma classificação das formas de governo derivadas delas. Segundo Mosca, embora inexata essa foi extremamente influente ${ }^{5}$. Embora seus antecedentes pudessem ser encontrados em tempos remotos, o estudo científico da política não era tão velho assim. O próprio Niccolò Machiavelli, indicado por muitos como o fundador da ciência da política, havia, segundo Mosca, se dedicado ao estudo dessas tendências constantes, empenhando-se de modo mais decisivo na pesquisa das artes

5 Esse tema foi objeto de análise na Teorica (cf. Mosca, 1982a, cap. I). 
"pelas quais um homem ou uma classe de pessoas podiam chegar a dispor do supremo poder em uma dada sociedade e a defender-se contra os esforços daqueles que quisessem subtraí-lo" (Mosca, 1982b, p. 550).

Torna-se evidente a consciência de Mosca a respeito da fundação de uma nova ciência, a ciência política, e a importância que atribuía a si nesse empreendimento. A necessidade de distingui-la das demais se tornava imperiosa, daí a recusa da ideia de sociologia proposta por Auguste Comte na Lição XLVII de seu Cours de philosophie positive em substituição ao conceito de fisiologia social ${ }^{6}$. Sobre essa ideia, a denominação de ciência política tinha o mérito de ser mais antiga e, o mais importante, permitia demarcar mais claramente seu objeto, uma vez que a sociologia "não tem ainda uma significação bem determinada e precisa e, no uso comum compreende todas as ciências sociais, entre as quais também a economia e aquelas que têm por objeto o estudo das leis que determinam a delinquência, ao invés de apenas aquela que tem por seu escopo principal o exame dos fenômenos que mais propriamente e especialmente se denominam políticos" (Mosca, 1982b, p. 552).

Tratava-se não apenas de definir o objeto particular dessa nova ciência, distinguindo-a das demais ciências sociais, como também de construir um método apropriado. Mosca se via, assim, na obrigação de rejeitar as visões mais cruas do naturalismo e do positivismo, além de recusar tanto aquelas abordagens que pretendiam deduzir os fenômenos políticos a partir da variedade do ambiente físico, particularmente do clima, como aquelas que enfatizavam as diferenças físicas e psicológicas entre as diferentes raças humanas ${ }^{7}$. Essas abordagens seriam, para Mosca, desmentidas pelos fatos. Seria possível encontrar na história das civilizações inúmeros exemplos que contradiriam tanto a superioridade dos povos dos altiplanos, das regiões montanhosas e dos climas temperados, afirmadas por alguns autores, quanto a supremacia intelectual e moral das raças arianas, defendida por outros estudiosos.

A esses métodos alinhados com o espírito científico da época Mosca contrapôs o método histórico. Não deixa de ser paradoxal que o autor dos

6 "Creio ser possível usar, a partir de agora, este novo termo, equivalente à minha expressão, já assinalada, de física social, para poder designar por um nome único esta parte complementar da filosofia natural que se relacionada ao estudo positivo do conjunto das leis fundamentais específicas aos fenômenos sociais" (Comte, 1939, t. 4, p. 252).

7 Enquanto Montesquieu era, obviamente, o autor mais importante e influente da abordagem naturalista, Gobineau poderia exemplificar a abordagem etnológica ou evolucionista da política. Ambas as perspectivas eram correntes na Itália do século XIX para explicar as diferenças entre o Sul e o Norte do país. 
Elementi di scienza politica propusesse para uma nova ciência um método que ele próprio considerava antigo: "Qualquer que possa ser no futuro a eficácia prática da ciência política é indiscutível que os progressos desta disciplina são totalmente fundados sobre o estudo dos fatos sociais e que estes fatos não podem ser extraídos senão da história das diversas nações. Em outras palavras, se a ciência deve ser fundada sob o estudo e a observação dos fatos políticos é ao antigo método histórico que é necessário retornar" (Mosca, 1982b, p. 597, grifos meus).

O método histórico assumiria para o estudo da política a mesma posição ocupada pelo método experimental nas ciências sociais. Do mesmo modo como este último teria permitido à física, à química e à biologia libertarem-se da astrologia, da alquimia e da teologia, o método histórico permitiria à ciência política afastar-se de modelos preconcebidos de organização social. Não apenas o impacto desses métodos sobre o conhecimento seria análogo como também seus resultados. Ambos teriam como consequência a coleta de um grande número de dados e informações capazes de permitir o teste das hipóteses científicas.

O historiador interessado na descoberta das leis e tendências da política não estaria interessado em toda pesquisa histórica e sim naquela que lhe permitiria encontrar regularidades comprováveis. Por isso mesmo, não seria nos pequenos fatos anedóticos e biográficos que pululavam na obra de certos historiadores que o cientista político prestaria atenção, mas naqueles fatos referentes "ao tipo de organização social dos vários povos e das várias épocas" (Mosca, 1982b, p. 601). Desse modo evitar-se-ia a vã investigação sobre fatos irrelevantes para a vida política. A pesquisa que interessaria à ciência política não seria a história dos indivíduos; seria a história das instituições (cf. Bobbio, 2002, p. 200-1). Esse interesse permitiria ao cientista político afastar-se de questões de difícil comprovação e aproximar-se daqueles fatos do passado que facilitariam a investigação das leis que determinariam a ação das massas:

Ninguém conhecerá nunca precisamente quais eram os erros e os méritos de Temístocles, como eram pronunciados os discursos de Péricles, qual era a perna da qual mancava Agesilao, a raça do cão de Alcebíades e a cor do cavalo de Alexandro Magno, mas é indiscutivelmente provado que na Hélade, do século sexto ao quarto antes de Cristo, existia um tipo de organização política da qual já conhecemos bem e conheceremos sempre melhor o desenho administrativo, econômico e militar (Mosca, 1982b, p. 601). 
A atenção do cientista político deveria recair, assim, nas instituições administrativas e jurídicas, na religião e nos hábitos morais e políticos dos povos e nações, uma vez que nestes seria possível encontrar a ação das grandes leis psicológicas que orientariam a ação das massas humanas. Para Mosca, a descoberta dessas leis exigiria não apenas ir além da história dos indivíduos, como também transcender na pesquisa o âmbito restrito de um único grupo de organismos políticos, de um mesmo período histórico e de um mesmo tipo de civilização. Apenas nas grandes sociedades humanas - na nação, no povo e no Estado - seria possível encontrar de modo desenvolvido as forças psicológicas que garantiriam a regularidade de certos fenômenos políticos. Nas relações políticas e morais em grande escala entre os homens essas forças se manifestariam e poderiam ser estudadas. O estudo deveria, assim, assumir o caráter de uma investigação comparativa de um número considerável de organismos políticos em um período de tempo vasto e em um abrangente número de civilizações. Desse modo, seria possível observar as regularidades existentes e enunciá-las sob a forma de leis, deixando para trás os vários métodos e sistemas de ideias que não tinham por objetivo senão criar "uma justificação mais ou menos filosófica, teológica ou racional de certos tipos de organização política" (Mosca, 1982b, p. 552-5).

Afastando-se dos estudos jurídicos e da filosofia política, tanto na definição de um objeto distinto de pesquisa como no método apresentado para levar a cabo tal investigação, Gaetano Mosca assentou as bases para a afirmação de uma nova scienza politica. O uso consciente que fez de expressão no singular, evitando a noção de scienze politiche, muito em voga na época, revela claramente o propósito de afirmar um novo campo específico do conhecimento. Com esse uso, o autor pretendia destacar que a política não apenas era um objeto particular, mas também deveria ser estudada com um método próprio.

\section{Vilfredo Pareto e a busca de uma sociologia da política}

A formação e o percurso intelectual de Vilfredo Pareto foram muito diferentes daqueles de Gaetano Mosca. Pareto estudou engenharia na Università di Torino, depois de formado iniciou suas atividades profissionais na Società delle Strade Ferrate Romana e posteriormente passou a trabalhar na Società per l'Industria del Ferro. Muito presente nos debates políticos e econômicos, a partir do início da década de 1870, era amigo do ativo casal de liberais 
florentinos Ubaldino e Emilia Peruzzi e participou da fundação da Società Adamo Smith, a qual tinha por objetivo divulgar as ideias do livre-cambismo por meio da revista L'Economista, claramente inspirada em sua homônima inglesa ${ }^{8}$. Sua formação o levou a procurar um tratamento científico para os problemas da época, mas rapidamente se separou das abordagens metafísicas e positivistas que predominavam em seu ambiente cultural.

Sua intensa agitação política e sua aguda intervenção nas discussões a respeito da política econômica o colocaram em contato com o economista Maffeo Pantaleoni, com o qual estabeleceu uma longa amizade. Foi por intermédio de Pantaleoni que Pareto obteve o emprego de professor de economia política na Universitè de Lausanne, ocupando a cadeira que já havia sido de Leon Walras. Mas a entrada de Pareto na vida acadêmica foi tardia. Quando assumiu seu posto em Lausanne, em 1893, já tinha 48 anos e foi somente três anos depois que publicou sua primeira obra de fôlego, o Cours déconomie politique . O impacto da obra foi, entretanto, imediato e o novo professor rapidamente ganhou fama. O livro tinha início com uma frase de grande força, a qual anunciava uma tese a respeito das ciências sociais que não seria mais abandonada pelo autor: "A ciência da qual empreendemos o estudo é uma ciência natural, como a psicologia, a fisiologia, a química etc. Como tal não deve dar preceitos; estuda primeiramente a propriedade natural de certas coisas e resolve depois os problemas que consistem em perguntar-se: dadas certas premissas, quais serão as consequências?” (Pareto, 1949 , v. I, $\$ 1$, p. 9-10).

Para deixar explícita sua opinião a esse respeito, o Cours recolocou mais adiante o mesmo problema em uma fórmula provocativa: "Considera-se o fenômeno social como o astrônomo considera o movimento dos astros, ao qual não pode impor nenhuma mudança. Recolhem-se os fatos, classificam-se, procura-se encontrar leis empíricas ou racionais" (Pareto, 1949, v. II, $\$ 574$, p. 573). Sua formação em engenharia e o amplo conhecimento da matemática, física e química imprimiram em seu discurso um conteúdo fortemente cientificista, no qual abundavam as analogias e as metáforas

8 Para a biografia de Pareto, ver Busino $(1974,1980)$ e Bonetti (1994). Para o importante período turinês, ver o ensaio de D'Orsi (2000).

9 As primeiras edições de Pareto são ora em francês, ora em italiano. Referimo-nos, assim, aos textos de acordo com o idioma da primeira edição, embora por razões de comodidade e facilidade de acesso citemos preferencialmente edições em italiano, publicadas pela Utet, e ocasionalmente as edições em francês das Fuvres, publicadas pela Droz, ambas a cargo de Giovanni Busino. 
derivadas das ciências naturais. Ao enfatizar os procedimentos das ciências naturais com os quais se encontrava familiarizado desde a juventude, Pareto recusava explicitamente a possibilidade de deduzir fatos hipotéticos de princípios a priori, como, segundo afirmava, haviam feito Bossuet, Hutcheson, Rousseau ou mesmo Platão.

Mas, ao contrário de Mosca, não era no método histórico que Pareto procurava a solução. No Cours são recorrentes suas críticas à escola histórica alemã, muito influente no debate econômico italiano. Tais críticas levaram Pareto a uma rejeição do próprio método histórico. De acordo com o Cours, esse método confundia-se muito facilmente com o empirismo e poderia conduzir a resultados muito equivocados. Pareto não recusava a observação como um método válido para a investigação nas ciências sociais e, dentre elas, a economia. Mas a observação não deveria excluir a dedução lógica. Para o professor de Lausanne, nos estudos da escola histórica a parte válida consistiria nas densas descrições dos eventos passados, mas seu ponto frágil seria justamente a parte dedutiva e prospectiva, a qual, quando tinha lugar, era sempre muito fraca (Pareto, 1949, v. II, \$577-8, p. 575-6).

Nem sempre seria possível prever o futuro com base no movimento do passado, afirmava Pareto. Se a evolução no tempo de um certo fenômeno não fosse uniforme, o que frequentemente aconteceria com os fenômenos sociais, não seria possível prever o desenvolvimento ulterior deste. Nesse caso, a previsão do futuro com base no passado induziria ao erro. O método histórico ou empírico se revelaria eficaz apenas para explicações retroativas do passado, mas não para formular previsões. O projeto paretiano era, nesse momento, o da afirmação de uma economia política pura, a qual definiria a forma geral dos fenômenos econômicos, forma esta que deveria ser julgada em base a fatos gerais e médios e não em base a ocorrências acidentais ( $\mathrm{Pa}$ reto, 1949 , v. I, $\$ 35$, p. 25).

No estudo da economia pura era necessário destacar a complexidade dos fenômenos sociais. As condições econômicas, intelectuais e morais existentes em uma sociedade guardariam sempre entre si uma relação de mútua dependência. Essa complexidade social impediria determinar os fenômenos que constituiriam o equilíbrio social e econômico a partir de uma quantidade restrita de condições consideradas em número necessário e suficiente (Pareto, 1949, v. II, $\$ 593$, p. 516 e $\$ 605$, p. 520-1). O argumento de Pareto estava voltado contra os reformadores sociais que acreditariam 
bastar definir uma forma apropriada de governo ou de leis para estabelecer esse equilíbrio; contra, também, as teorias antropológicas ou sociológicas, que considerariam a influência preponderante da raça e dos fatores sociais; e mesmo contra as interpretações religiosas ou filosóficas que atribuiriam às crenças e ideias de um povo as razões de seu progresso. Em suma, o que o autor do Cours rejeitava eram as concepções consideradas fatalistas, as quais ressaltariam uma das condições que determinariam os fenômenos sociais e omitiriam todas as demais (Pareto, 1949, v. II, $\$ 606$, p. 622-3).

A investigação de Pareto sobre a economia política sediada no Cours já indicava uma direção que o levava para além desse campo disciplinar. $\mathrm{O}$ Livro II da obra era dedicado àquilo que denominava de "organismo econômico", e uma parte considerável de seu estudo se dirigia para a análise dos "princípios gerais da evolução social" e, dentre estes, do "equilíbrio econômico e o equilíbrio social” (Pareto, 1949, cap. I). O professor de Lausanne considerava que a sociedade encontrar-se-ia em "um estado de equilíbrio, de equilíbrio social” (Pareto, 1949, v. II, $\$ 585$, p. 511). Este não era, entretanto, um equilíbrio estático, e sim dinâmico, uma vez que a sociedade possuiria um movimento geral que a modificaria lentamente, o qual habitualmente era denominado de evolução. A ciência que propunha deveria ter como objeto de investigação esse equilíbrio dinâmico da sociedade.

O empreendimento paretiano visava construir uma teoria do equilíbrio social na qual o equilíbrio econômico fosse um de seus aspectos. A abordagem abrangente que o professor de Lausanne adotou no estudo dos fenômenos econômicos e sua insistência na pluralidade e na interdependência das causas dos fenômenos sociais expressavam-se em um tratamento dos problemas sociais e econômicos que hoje poderíamos chamar de interdisciplinar. A necessidade de ir além da economia política se manifestou para o autor do Cours não como uma consequência posterior de seus estudos, mas como uma exigência da própria pesquisa. Desse modo teve início a investigação que levou Pareto da economia pura a uma teoria geral da sociedade.

Em julho de 1897, pouco após a finalização do Cours d'economie politique, Pareto publicou na Rivista italiana di sociologia sua apresentação ao curso de sociologia da Universitè de Lausanne. A apresentação retomava temas tratados no Cours, expondo-os, entretanto, no interior de um projeto mais abrangente. $\mathrm{O}$ objetivo explicito da pesquisa era, agora, estudar a sociedade humana "como se não fizéssemos parte dela", eliminando "o elemento sub- 
jetivo da pesquisa” (Pareto, 1980, p. 130). Essa investigação exigia, como Pareto logo constatou, ir além da abordagem econômica. Embora esta fosse importante, permitia apenas um conhecimento parcial de certos aspectos da vida social. Estudar a sociedade humana em toda sua abrangência e complexidade era o propósito da sociologia, à qual caberia unificar todas as ciências que estudam as várias categorias específicas de fenômenos sociais. A sociologia era considerada, assim, uma "ciência geral" (Pareto, 1980, p. 131) ${ }^{10}$.

Essa não foi a última solução que esse autor deu para o problema da relação da sociologia com as ciências particulares, como se pode ver em dois importantes textos publicados em 1906 - "Il metodo nella sociologia" e "Programma e sunto di un corso di sociologia" (cf. Pareto, 1980, p. 279-91 e 292-316). Neles, o professor de Lausanne afirmava que a sociologia deveria, em um sentido abrangente, "abarcar o estudo de tudo o que pertence ao ordenamento da vida", ao desenvolvimento da sociedade humana (Pareto, 1980, p. 279-81 e 292). Desse modo, a sociologia deveria incorporar a economia política, o direito, a ciência das religiões e outras disciplinas já constituídas de maneira independente e rigorosa. Mas a esse conceito amplo do objeto da sociologia Pareto sobrepunha outro, circunscrito e adaptado às necessidades da pesquisa, segundo o qual caberia a essa ciência: “1) o estudo sintético das sociedades humanas. E, para obtê-lo, vale-se dos resultados aos quais chegaram as ciências particulares; 2) o estudo de ramos que ainda não se destacaram da sociologia" (Pareto, 1980, p. 280 e 292-3).

Tal maneira de colocar o problema, na qual se preservava a independência dos ramos particulares do conhecimento, foi a forma mais acabada de exposição, na obra de Pareto, da relação entre as diferentes ciências sociais. $\mathrm{O}$ método da sociologia encontrava-se nesse ponto bastante desenvolvido. No Manuale di economia politica, publicado por Pareto em 1906, retomava-se a reflexão a respeito da construção de um conhecimento científico, afirmando que o objetivo da economia política e da sociologia seria "pesquisar e traçar as uniformidades que apresentam os fenômenos, quer dizer, suas leis [...], sem visar nenhuma utilidade prática direta, sem se preocupar de modo algum em dar receitas ou preceitos, sem mesmo buscar a felicidade, a utilidade ou o bem-estar da humanidade ou de uma de suas partes." (Pareto, 1919, p. 3). Apenas a existência dessas uniformidades permitiria aplicar um tratamento

10 Pareto denominou sua obra máxima, publicada em 1916, de Trattato di sociologia generale. 
científico a esses campos do conhecimento. O objetivo da ciência seria, pois, o estudo das leis que regeriam os fenômenos sociais.

O conceito de lei científica utilizado por Pareto, entretanto, distinguia-se das abordagens positivistas mais rudimentares. Para o autor do Manuale, não poderia haver exceções para as leis econômicas ou sociológicas. $\mathrm{Na}$ medida em que uma uniformidade não uniforme não faria sentido, "as leis científicas não têm uma existência objetiva” (Pareto, 1919, p. 7). A imperfeição do conhecimento levaria o senso comum a falar de "exceções". Mas tais "exceções" não seriam senão lacunas do intelecto, ou seja, resultado do desconhecimento de outros fenômenos superpostos ao fenômeno estudado. Pareto concluía afirmando a impossibilidade de conhecer todos os aspectos de um fenômeno concreto e o consequente caráter aproximativo das teorias com uma formulação que lembra os tipos ideais weberianos: "Já que não conhecemos inteiramente nenhum fenômeno concreto, nossas teorias sobre esses fenômenos são somente aproximativas. Conhecemos apenas fenômenos ideais, que se aproximam mais ou menos dos fenômenos concretos" (Pareto, 1919, p. 9).

Embora em vários momentos de sua obra Pareto tenha destacado o caráter experimental de seu empreendimento, foi apenas com a publicação do Trattato di sociologia generale, em 1916, que este adquiriu uma forma final. Como em outras ocasiões e do mesmo modo que Gaetano Mosca, Pareto começava essa obra sentenciando que desejava utilizar, no estudo da sociologia, "os meios que foram tão úteis no estudo de outras ciências" (Pareto, 1988, v. I, $\$ 5$, p. 56). Essa afirmação permitia ao autor excluir da apresentação inicial aquilo que considerava serem os dogmas sobre os quais a sociologia havia até então sido construída. Da crítica não escapavam sequer Augusto Comte e Herbert Spencer, cujas sociologias teriam sido expostas dogmaticamente e, por isso mesmo, assemelhavam-se a uma forma de religião (Pareto, 1988, p. 57). O autor do Trattato escrevia contra tudo e contra todos. Por um lado, rejeitava firmemente os ataques contra a ciência provenientes do neoidealismo italiano e do historicismo alemão preponderantes; por outro afastava-se decididamente dos principais expoentes do pensamento positivista. Deixando de lado as premissas dogmáticas que organizariam a obra dos autores e escolas precedentes, Pareto propunha apresentar uma sociologia "exclusivamente experimental, como a química, a física e outras ciências similares” (Pareto, 1988, §6, p. 58). Para tanto, as únicas guias se- 
riam “a experiência e a observação" (Pareto, 1988, p. 59). Afirmava, assim, a sociologia como uma "ciência lógico-experimental" da "relação entre os fatos sociais" (Pareto, 1988, \$3, p. 54 e $\$ 19$, p. 67).

A afirmação precedente permite compreender a distância que separava a formulação mais madura de Pareto daquelas primeiras investigações, que tiveram lugar no âmbito da economia e, particularmente, da economia pura. A investigação dos nexos lógicos entre os fatos sociais ainda mantinha sua importância, mas o ponto de partida era, agora, os próprios fatos sociais, o “material experimental" (Pareto, 1988, \$13, p. 61). Daí que a relação entre esses fatos passasse a ser pesquisada "nos limites do espaço e do tempo por nós notados" e baseada na "interrogação à experiência" (Pareto, 1988, § 19, p. 67). Pareto imaginava que essa abordagem permitia tomar distância da metafísica e do arraigo desta aos princípios e raciocínios abstratos, mas também permitia precaver-se contra os exageros do dedutivismo característico da economia pura: "Enquanto a metafísica desce dos princípios absolutos aos casos concretos, a ciência experimental vai dos casos concretos não mais aos princípios absolutos, que para ela não existem, mas apenas aos princípios gerais, que depois se fazem depender de outros mais gerais e assim indefinidamente" (Pareto, 1988, §22, p. 69).

A relação entre princípios e fatos era, assim, subvertida. Para as teorias metafísicas, positivas ou não lógico-experimentais, os princípios seriam definições a priori que independeriam dos fatos perceptíveis pela experiência humana. Nessas perspectivas, a independência dos princípios permitiria afastá-los de qualquer tentativa de validação deles por meio da análise da adequação de suas consequências à experiência. Para os metafísicos, quando os princípios e a experiência estivessem em desacordo, esta última teria falhado ou produzido uma forma de conhecimento inferior, particular e relativa, não absoluta e universal como aquela que surgiria dos primeiros. $\mathrm{Na}$ perspectiva lógico-experimental proposta por Pareto os princípios seriam proposições abstratas que condensariam as características comuns de muitos fatos apreendidos mediante a experiência. A raiz dos princípios estaria, assim, nos fatos e não o contrário, como se propõe frequentemente (Pareto, 1988, §\$ 55-6, p. 81-2). ${ }^{11}$

11 Pareto não recusava o uso de hipóteses como meio de demonstração que não recorresse à verificação experimental ou mesmo independesse dela. Esse poderia ser um recurso válido em certas pesquisas nas quais essa verificação seria muito difícil ou mesmo impossível. O que ele recusava é que essas 
A análise das elites, tema central de sua reflexão política a partir do início do século XX, permite ilustrar o método lógico-experimental exposto por Pareto. Entre os fatos aos quais ele prestou mais atenção e que compõem parte considerável do corpus de suas observações estão aqueles próprios da vida política: quem governa? Como governa? Ao grande número de escritos políticos paretianos publicados desde os anos 1870 devem se somar algumas obras de maior fôlego, como: Les systèmes socialistes, de 1902; a coletânea Fatti e teorie, de 1920; Trasformazione della democrazia, de 1921; ou mesmo o Trattato, que contém vasto material de análise da política italiana. Embora Pareto não propusesse a fundação de uma ciência política, suas pesquisas o conduziram a uma sociologia da política, e pode-se afirmar que a política foi o verdadeiro campo de provas de sua sociologia.

A pesquisa sobre as elites apareceu de modo mais sistemático apenas tardiamente no pensamento paretiano e quase quinze anos depois de Gaetano Mosca ter anunciado sua teoria da classe política. Esses quinze anos permitem compreender os diferentes objetivos das duas abordagens. Quando o ex-aluno do corso complementare escreveu sua Teorica, em 1883, o fez como um partidário da Destra Storica que via com profunda decepção os primeiros anos de governo da Sinistra. Sua obra apresentava um quadro de grande ceticismo sobre o futuro das classes dirigentes italianas e uma condenação radical do regime parlamentar e a sua incapacidade de selecionar os melhores para o governo. O fenômeno político que Pareto tinha em mente quando esboçou sua teoria das elites era outro: a emergência do socialismo.

Habitualmente afirma-se que Pareto formulou pela primeira vez essa teoria em Les systèmes socialistes, de 1902. Mas em um importante artigo, intitulado "Una applicazione di teorie sociologiche" e publicado em 1900 na Rivista Italiana di Sociologia, já era possível encontrar uma primeira formulação em termos muito próximos daqueles que apareceriam dois anos mais tarde: "Os povos, salvo breves intervalos de tempo, são sempre governados por uma aristocracia, [...] os mais fortes, enérgicos e capazes, tanto para o bem, como para o mal" (Pareto, 1980, p. 186). Além de afirmar o governo de uma aristocracia como a forma mais frequente de governo, o professor de Lausanne apresentou duas outras importantes hipóteses nesse ensaio: 1) “as aristocracias não duram”; 2) “a história humana é a história da alternância dessas aristocracias” (Pareto, 1980).

hipóteses pudessem ser afirmadas como propriedades essenciais do objeto ou condições necessárias do movimento desse objeto (cf. Pareto, 1988, §59, p. 83). 
A preocupação com a difusão das ideias socialistas já se encontrava presente nesse texto. Pareto considerava que uma das manifestações do declínio de uma aristocracia era a emergência de novos fenômenos religiosos. $\mathrm{O}$ socialismo seria uma das formas que a religião assumiria no mundo contemporâneo. A pesquisa a respeito desses sistemas de crenças, sentimentos e fé que acompanhavam o surgimento de uma nova aristocracia era anunciada por Pareto. Essas ideias, apresentadas in nuce, encontraram desenvolvimento posterior em Les systèmes socialistes, obra de 1902 que apresentava a teoria das elites de modo desenvolvido e na qual a análise dessa "religião do socialismo" ocupou um lugar central. Escrevendo uma obra que reputava científica, o autor afirmava que se encontrava no campo do raciocínio e da razão, mas isso não implicaria uma negação "da existência do campo do sentimento e da fé” (Pareto, 1974a, p. 128). O desafio para o pesquisador estaria em distinguir os fenômenos subjetivos dos fenômenos objetivos e submeter ambos a uma análise objetiva.

A pesquisa de Pareto era orientada por certos "princípios de fisiologia social" (Pareto, 1974a, p. 129). Partindo da análise presente no Cours sobre a distribuição da riqueza, o professor de Lausanne afirmou que em uma curva de distribuição que dispusesse os indivíduos "segundo seus graus de influência e poder político e social”, os mesmos indivíduos ocupariam os mesmos postos tanto nessa curva, como "naquela da distribuição da riqueza". Pareto concluia seu argumento afirmando que "as classes ditas superiores são geralmente também as mais ricas. Estas classes constituem uma élite, uma aristocracia" (Pareto, 1974a, p. 131).

Tal élite não seria, entretanto, eterna. De grande importância para a análise de Pareto era a tese de que "as aristocracias não duram" (Pareto, 1974a, p. 131). Ele estava interessado em analisar o processo de circulação das elites, ou seja, a substituição de velhas elites por novas. As novas elites, acreditava, nasceriam dos estratos inferiores da sociedade e se expandiriam, substituindo as aristocracias precedentes para, a seguir declinarem mais uma vez e serem novamente substituídas por elites ainda mais novas. A circulação das elites era, segundo Pareto, o resultado dos conflitos que oporiam duas aristocracias diferentes e não uma aristocracia, sempre a mesma, ao povo: "Ora, em efeito: $1^{\circ}$ trata-se de uma luta entre uma aristocracia e uma outra; $2^{\circ}$ a aristocracia no poder muda continuamente, sendo aquela de hoje substituída, depois de um certo período de tempo, pelos seus adversários" (Pareto, 1974a, p. 153). 
Esse processo de circulação das elites seria frequentemente um "fenômeno objetivo concreto", que deveria ser distinguido das formas por meio das quais o espírito o conceberia e interpretaria (Pareto, 1974a, p. 136). Mas, para o pesquisador, tanto o "fenômeno objetivo" como o "fenômeno subjetivo" da interpretação precisariam ser investigados. Foi o que Pareto procurou fazer em sua obra:

Por um lado pesquisaremos quais são os fatos reais que favoreceram a fundação de certos sistemas sociais ou o nascimento de projetos de sistemas sociais, em outros termos, quais são as coisas e os fatos que se revelam sob esta forma; por outro, examinaremos os raciocínios de que se fez uso para justificar esses sistemas ou esses projetos de sistemas e veremos até que ponto as premissas são extraídas da experiência e as deduções são lógicas (Pareto, 1974a, p. 144).

A pesquisa de Pareto dizia respeito então ao surgimento de novas elites operárias e socialistas e à fundação dos sistemas socialistas como formas ideais voltadas a justificar a ascensão dessas novas elites. Giovanni Busino argumentou que Les systèmes socialistes era uma certa "autobiografia espiritual" de seu autor (Busino, 1968, p. 45). Embora Pareto pretendesse impedir que seus próprios sentimentos influenciassem a pesquisa, ela foi uma de suas obras mais engajadas politicamente. Quando foi publicada, Giovanni Giolitti (1842-1928) já havia exercido seu primeiro mandato como chefe de governo e se preparava para um segundo ${ }^{12}$. A política de Giolitti, claramente trasformista, procurava integrar as alas moderadas do Partito Socialista à sua base parlamentar por meio de consideráveis concessões ao movimento sindical. Fenômenos similares ocorriam em outros países. Na França, o socialista Alexandre Millerand (1859-1943) assumia o Ministère du Commerce, de l'Industrie et des Postes et Télégraphes no governo dito de défense républicaine de Pierre Waldeck-Rousseau (1846-1904), durante a crise do affaire Dreyfuss. Até mesmo na Inglaterra as ideias liberais pareciam ser deixadas para trás e não foram poucas as seções do Liberal Party que

12 Giolitti foi chefe de governo em nove diferentes períodos: de 15 de maio de 1892 a 27 de setembro de 1892; de 23 de novembro de 1892 a 15 de dezembro de 1893; de 3 de novembro de 1903 a 18 de outubro de 1904; de 30 novembro de 1904 a 12 de março 1905; de 29 de maio de 1906 a 8 de fevereiro de 1909; de 24 de março de 1909 a 11 dezembro de 1909; de 30 de março de 1911 a 29 de setembro de 1913; de 27 de novembro de 1913 a 21 de março de 1914; de 15 de junho de 1920 a 7 de abril de 1921; de 11 de junho de 1921 a 4 de julho de 1921. 
acolheram candidaturas apoiadas pelos sindicatos, as quais chegavam ao parlamento como representantes dos interesses das classes trabalhadoras.

Todos esses movimentos políticos haviam sido analisados por Pareto em seus escritos políticos, mas a impostação em Les systèmes socialistes era diferente ${ }^{13}$. Em sua obra de 1903, a investigação era assumidamente a respeito das causas da emergência e expansão desses sistemas de ideias, sentimentos e crenças e da consistência das premissas desses sistemas com a experiência e a lógica. Mas o empreendimento todo era politicamente orientado. Era em torno dos efeitos esperados desses sistemas socialistas sobre a vida social e política dos países que a pesquisa se organizava e era aos resultados dos processos contemporâneos de circulação das elites que o olhar curioso de Pareto se dirigia.

\section{Experiência, experimento e observação}

Mosca e Pareto romperam definitivamente com os estudos jurídicos, afastaram-se da investigação sobre o direito público e afirmaram um objeto próprio para a análise política. A grande contribuição da obra desses autores foi a revalorização da tradição maquiaveliana e a consequente mudança de foco das instituições jurídicas para o estudo da ação e do conflito político. Esse deslocamento temático já havia sido esboçado por autores precedentes. Outros já haviam afirmado, como Attilio Brunialti (1849-1920), que "na vida tudo é luta, contraste furioso, conflito estridente" (Brunialti, 1896, p. 141). Mas uma coisa era reconhecer a existência do conflito político, outra era fazer dele o objeto de uma ciência. Reencontrando na ação e no conflito o objeto de uma ciência, Mosca e Pareto procederam a uma verdadeira

13 Em um conjunto de artigos imediatamente precedentes a Les systèmes socialistes, Pareto defendeu a unidade entre os liberais e os socialistas como uma maneira de fazer frente à acelerada decadência da burguesia e defender a liberdade que esta ameaçava. Questionado se os socialistas não queriam um Estado dos proletários, o professor respondeu: "Na Itália, um Estado desse tipo já foi constituído, salvo que os interesses que tutela, ao invés de serem aqueles dos proletários, são de uma parte da burguesia e de certos políticos" (Pareto, 1974b, p. 321; cf. também p. 285-9 e 312-6). A atitude de Pareto mudou consideravelmente à medida em que o movimento grevista apoiado pelos socialistas ganhou vigor. Em 1904, protestando contra as greves dos ferroviários e dos professores, o professor de Lausanne escreveu nas páginas do reacionário e misógino jornal // Regno: "O partido revolucionário socialista provavelmente vencerá porque é o único, ou praticamente o único, que não tem repugnância de recorrer à força; a qual, desde que existe este mundo é a única que conserva e assegura a vitória. E enquanto os humanitários burgueses, como mulherzinhas ineptas, caem desmaiados apenas ao sentir discorrer de derramamento de sangue, os revolucionários sabem que tudo o que existe foi o produto de batalhas que certamente não foram incruentas" (Pareto, 1974b, p. 435). A partir desse ponto passou a defender o uso da força e da violência contra os sindicalistas para "defender a liberdade". 
revolução intelectual, mas no que diz respeito às definições metodológicas, estas permaneceram na obra desses autores imprecisas e indeterminadas.

Em Mosca a ciência era o resultado da observação sistemática, organizada e controlada. A ciência matemática era o modelo mais simples e fonte de inspiração para um verdadeiro método científico. Os axiomas que lhe serviriam de base seriam frutos da observação acessível a todos. A partir da coordenação desses axiomas seria possível chegar a teoremas simples e, depois, coordenando-os com os axiomas, a teoremas mais complexos, até chegar àqueles que só seriam compreensíveis aos iniciados (Mosca, 1982b, p. 533). Em outras formas de conhecimento, como a da física ou das demais ciências naturais, isso nem sempre seria possível, e a observação simples deveria ser substituída por um "experimento" ou por "longa experiência" (Mosca, 1982a).

Tanto o experimento como a experiência requereriam "métodos especiais e adequados". O desenvolvimento científico teria exigido o "aperfeiçoamento dos métodos e dos instrumentos materiais de observação", que teriam permitido recolher os abundantes dados a partir dos quais cientistas treinados poderiam formular hipóteses consistentes (Mosca, 1982b, p. 553-4). Mosca insistiu na qualidade dos métodos utilizados e dos dados obtidos. Para chegar a essas hipóteses consistentes não bastaria que se procedesse "com o sistema da observação e da experiência”. Seria necessário que esse sistema fosse operado de acordo com os métodos e regras de pesquisa que garantissem os bons resultados e não apenas sua aparência e sua forma. Mas esse autor, entretanto, não foi além desse ponto. Percebe-se que não distinguia experimento de experiência e que ambos costumavam ser aproximados da observação.

Imprecisões semelhantes encontram-se na obra de Pareto, embora ele fosse mais minucioso na exposição do método do que seu contemporâneo. Apesar de sempre procurar definir de modo preciso os conceitos e expô-los de maneira sistemática, sua apresentação do método era extensa, mas pouco rigorosa. A ambiguidade na terminologia empregada era grande. $\mathrm{O}$ autor do Trattato utilizava como sinônimos, por exemplo, "material experimental [materiale sperimentale]" e "experiência [esperienza]" em uma importantíssima passagem, na qual definia o tipo de conhecimento lógico-experimental (Pareto, 1988, $₫$ 13, p. 62). Mas a sinonímia precisaria ser explicada ou, ao menos, justificada. Nas ciências naturais, um experimento implica, geralmente, a construção 
artificial de um sistema experimental, a indução de mudanças externamente controladas de certos parâmetros e a mensuração dos efeitos nos diferentes testes realizados. Certamente não era a respeito desses experimentos que Pareto escrevia. Em uma observação registrada em um escrito de 1918, no qual procurava definir a economia sperimentale, o professor de Lausanne explicou a ideia de uma ciência lógico-experimental: "o termo lógica aqui não requer explicação; mas ela cabe para o termo experiência. Esta indicará exclusivamente descrições de fatos e não os sentimentos subjetivos que queiram substituir os fatos ou dominá-los" (Pareto, 1980, p. 179).

Giovanni Busino procurou distinguir na obra paretiana observação de experiência e, desse modo, desfazer a confusão que frequentemente se estabelecia entre os dois termos. Por experiência, Pareto entenderia "uma ação e uma construção progressiva, uma estruturação gradual de nossas operações pela via da assimilação e da acomodação" (Busino, 2008, p. 109). A observação, por sua vez, consistiria "em considerar as coisas tal quais elas são, em descobrir suas propriedades e coordená-las, em reproduzi-las mentalmente" (Busino, 2008, p. 109). A observação seria, assim, o meio que permitiria a realização da experiência. Pareto destacou explicitamente é que a experiência científica era diferente da "experiência íntima cristã" e da "auto-observação dos antigos metafísicos” (Pareto, 1988, $\$ 69$, p. 90). Tratava-se, portanto, de um processo de rigoroso confronto das hipóteses formuladas com os fatos objetivamente apreendidos por meio do qual seria possível chegar a um conhecimento científico. Percebe-se, por fim, por que experiência e observação apareciam frequentemente juntas no texto paretiano.

Mas se não incorria no erro de identificar experiência e observação, como Mosca, Pareto ainda permanecia ambíguo com relação aos termos de experimento e experiência. Essa ambiguidade é surpreendente, uma vez que ele desde muito cedo esteve familiarizado com a literatura científica e fez profissão de fé em favor do método experimental. Em 1864 o jovem Pareto se inscreveu na Facoltà di Scienze, em Torino, para estudar matemática, e em 1867 entrou na Scuola di Applicazione per Ingegneri, na mesma cidade. A capital do Piemonte era um dos centros mais efervescentes da cultura positivista e ali o estudante tomou contato com um sofisticado pensamento e uma abordagem rigorosa dos problemas científicos (cf. D’Orsi, 2000). A tese de láurea apresentada por Pareto na Scuola, em 1869, traz uma importante observação em sua primeira página que atesta uma inesperada influência de 
Jacob Moleschott (1822-1893) sobre sua pesquisa ${ }^{14}$. Moleschott era diretor do laboratório de fisiologia experimental na Facoltà Medico-chirurgica della Regia Università di Torino. Com fama de materialista, o que despertou forte oposição quando de sua nomeação, o professor foi o artífice da renovação dos estudos em fisiologia na Facoltà e da divulgação do método experimental.

No primeiro capítulo de sua tese juvenil, Fritz Pareto, como era chamado e assinava, recusou as teorias que consideravam que os axiomas matemáticos puros prescindiriam de toda experiência e, por essa razão, não poderiam fundar as ciências físicas e matemáticas. Fazendo profissão de fé em uma teoria experimental da matemática, o jovem engenheiro afirmava, reivindicando a influência do fisiologista: "Creio, com um douto que é nosso concidadão, o professor Moleschott, que ao lado de todas as outras ciências a matemática se funda sobre a experiência e que não existam nela verdadeiros axiomas, mas verdades que uma longa experiência nos fez conhecer" (Pareto, 1869, p. 1) ) $^{15}$.

É possível afirmar que, seguindo caminhos diferentes, Mosca e Pareto chegaram ao mesmo lugar. $\mathrm{O}$ caráter impreciso do método e o uso ambíguo das noções de experiência e experimento revelam a incapacidade desses autores em ir além das técnicas de estudo da política predominantes na época. Ambos insistiram em que a ciência que pretendiam construir deveria ancorar-se na observação dos fatos e não na sua dedução a partir de princípios hipotéticos ${ }^{16}$. Mas o método experimental que reivindicavam não deixava de confundir-se com um inventário de experiências políticas presentes e passadas. A unidade metodológica entre as ciências naturais, a ciência política e a sociologia, insistentemente anunciada por esses autores, não parecia, desse modo, realizar-se como prometido. $\mathrm{O}$ suposto método experimental não implicava senão uma rigorosa pesquisa dos fatos, da veritá effettuale della cosa baseada em "uma longa experiência das coisas modernas e um contínuo estudo das antigas" (Machiavelli, 1971, p. 257). Era, assim, ao realismo maquiaveliano que ambos retornavam para fundar mais uma vez a ciência política italiana.

14 A tese intitulava-se Principj fondamentali della teoria della elasticità de'corpi solidi e ricerche sulla integrazione delle equazioni differenziali che ne definiscono l'equilibrio (Pareto, 1869).

15 Ver o comentário de D’Orsi (2000). A inclinação juvenil em direção às teorias experimentalistas tornar-se-ia mais marcante com o passar dos anos, e a intensificação do contato de Pareto com o ambiente cultural francês, a nova economia política e as novas ciências sociais que se desenvolviam nesse país. Importantes foram a leitura da obra do economista Yves Guyot (1843-1928), La science economique (1881), e de Léon Donnat (1832-1893), La politique experimentale (1885).

16 Ver, por exemplo, as observações de Norberto Bobbio a respeito de Gaetano Mosca (Bobbio, 2002, p. 197). 


\section{Conclusão}

A reconstrução dos percursos intelectuais de Mosca e Pareto permite compreender melhor o contraditório processo histórico de afirmação de uma ciência política como disciplina acadêmica científica. Embora ambos fizessem profissão de fé em um método experimental similar ao que fundava as ciências naturais, a aplicação desse método distanciava-se muito do modelo anunciado. Quais as razões, então, para continuarem insistindo na validade desse método na ciência política e na sociologia? Responder essa pergunta pode ajudar a compreender a persistente reivindicação do "método das ciências naturais" por cientistas políticos contemporâneos. A resposta pode ser encontrada em duas dimensões diferentes: uma científica propriamente dita e outra disciplinar.

Primeiro a dimensão científica. A defesa do método das ciências naturais para o estudo da política costuma estar baseada na afirmação de que existiria alguma forma de unidade de todas as ciências que poderia se expressar na existência de protocolos de validação (ou falseabilidade) do conhecimento comuns a todas as disciplinas. Essa ideia aparece de maneira explícita em um dos mais conhecidos manuais de metodologia das ciências sociais, cujos autores afirmam que o "conteúdo da 'ciência' são, primariamente, métodos e regras e não seu tema, uma vez que podemos usar esses métodos para estudar virtualmente qualquer coisa” (King, Keohane e Verba, 1994, p. 9).

Mas para os cientistas políticos, a finalidade última não é a aplicação de certos meios de obtenção do conhecimento e sim o próprio conhecimento obtido. A reivindicação do método científico das ciências naturais é, sempre, uma reivindicação da consistência do conhecimento produzido pelos cientistas políticos, ou seja, a afirmação de que ele também poderia passar pelos mesmos protocolos de validação ou falseabilidade das ciências naturais ${ }^{17}$. Trata-se de produzir um conhecimento da realidade política que possa ser partilhado por outros cientistas, independentemente dos valores ou das posições políticas destes. Mas, se essa é a finalidade, é preciso reconhecer que o método das ciências naturais não é o único caminho.

Compreende-se, assim, o modo como Mosca e Pareto podiam deixar de lado o método experimental das ciências naturais anunciado e adotar uma prática científica que valorizava as experiências passadas e presentes, sem

17 Nesse programa de trabalho científico há, obviamente, uma concepção ingênua das ciências naturais. Mas não é o objetivo deste artigo lidar com esse problema. 
com isso deixar de atingir objetivos de grande impacto, como foram suas teorias da classe política e das elites. Porque a finalidade nunca foi, de fato, a aplicação um método experimental strictu sensu, e sim a produção de um conhecimento científico consistente, para o qual o realismo político cumpria uma função metodológica fundamental.

A segunda dimensão é disciplinar. A defesa do método das ciências naturais para o estudo da política também pode ser um mecanismo de legitimação disciplinar. Em busca de reconhecimento na opinião pública, com todos os recursos financeiros e simbólicos que este implica, reivindicar o caráter científico do uma nova disciplina e apresentá-la como parte do desenvolvimento científico da época era uma operação crucial. A afirmação de uma nova ciência, como era a ciência política de Mosca ou a sociologia geral de Pareto, em um contexto fortemente marcado pela cultura positivista, implicava inserir esse empreendimento na correnteza daquelas ciências que já se encontravam consolidadas e gozavam de grande reputação, como as ciências naturais.

Um desenvolvimento análogo podemos encontrar no processo de constituição da ciência política nos Estados Unidos. Em suas memórias, John Burgess (1844-1931), que em 1880 fundou a School of Political Science da Columbia University, recordava a oposição que encontrou diante daqueles que "não consideravam nenhuma ciência além das ciências naturais e sentiam que estávamos gastando dinheiro dos fundos, o qual poderia ser aplicado de modo muito melhor" (Burgess, 1934, p. 210). Afirmar dessa maneira o caráter científico da ciência política e sua semelhança metodológica com as ciências naturais era, assim, um meio de garantir sua sobrevivência.

Mas uma coisa era fazer isso no momento de constituição da ciência política, outra é proceder dessa maneira quando esta já é um campo disciplinar plenamente consolidado e não necessita mais recorrer a uma fonte externa de legitimidade. Em uma situação como a presente, subordinar a ciência política ao método das ciências naturais é aceitar uma condição subalterna e heterônoma. Ou seja, implica aceitar que as ciências guardam entre si uma certa hierarquia e que o estudo da política ocupa nela uma posição inferior. Mas hoje essa não parece ser uma estratégia capaz de produzir bons resultados.

Portanto, a questão metodológica deve ser resolvida exclusivamente na dimensão científica. Aqui, a trajetória de Mosca e Pareto pode ajudar a pensar alternativas. Ambos escreveram a respeito de coisas que seus concidadãos estavam preparados para ler e faziam isso a partir daquilo que seus contemporâneos 
e seus antepassados viveram. É por esse motivo que, embora o método que anunciaram não tenha obtido muito sucesso, não fosse sempre coerente e seus proponentes não tenham se mantido fieis a ele, não se poderia dizer a mesma coisa de suas conclusões empíricas, as quais se mostraram consistentes e muito influentes. $\mathrm{O}$ fracasso do método experimental propugnado por esses autores não implicou um fracasso do realismo que eles operaram em suas pesquisas. Essa trajetória pode permitir compreender melhor não só as dificuldades próprias de um método experimental na ciência política, como também os potenciais existentes naquela revalorização do realismo maquiaveliano pela ciência política italiana do final do século XIX. Aí pode estar uma pista para enfrentar alguns dos dilemas que a ciência política contemporânea coloca para si.

\section{Referências}

ALBERTONI, Ettore A. (1985). Storia delle dottrine politiche in Italia. Milano: Mondadori,.

BAGIANTI, Ivo (1980). "Mussolini, Pareto e il fascismo". Revue Européene des Sciences Sociales, v. XVIII, n. 51, p.189-92.

BEDESCHI, Giuseppe (2002). La fabbrica delle ideologie: il pensiero político nell'Italia del novecento. Bari: Laterza.

BOBBIO, Norberto (1990). Profilo ideológico del'900. Milano: Garzanti,. (2002). Ensaios sobre ciência política na Itália. Brasília, São Paulo: Editora UnB, Imprensa Oficial do Estado.

BONETTI, Paolo (1994). Il pensiero politico di Pareto. Roma: Laterza.

BRUNIALTI, Attilio (1896). Il diritto constituzionale e la politica nella scienza e nelle instituzione. Torino: Unione Tipografico-Editrice.

BURGESS, John W. (1934). Reminiscences of an American scholar: the begginings of Columbia University. New York: Columbia University Press.

BUSINO, Giovanni (1968). Introdution a une histoire de la sociologie de Pareto. Genève: Droz.

(1974). "Introduzione e nota biografica”. In: PARETO, Vilfredo. I sistemi socialisti: a cura di Giovanni Busino. Torino: Utet.

(1980). "Introduzione e nota biografica". In: PARETO, Vilfredo. Scritti sociologici minori: a cura di Giovanni Busino. Torino: Utet.

(2008). "La science sociale de Vilfredo Pareto". Revue Européene des Sciences Sociales, v. XLVI, n. 140, p. 107-32.

CAMMARANO, Fulvio (1999). Storia política dell'Italia liberale. Bari: Laterza. 
CANDELORO, Giorgio (1970). Storia dell'Italia moderna: lo sviluppo del capitalismo e del movimento operaio. Milano: Feltrinelli.

COMTE, Auguste (1939). Cours de philosophie positive. Paris: Bachelier,.

D’ORSI, Angelo (2000). "Vilfredo Pareto e la cultura piemontese: note e appunti”. In: MALANDRINO, Corrado \& MARCHIONATTI, Roberto (cur.). Economia, sociologia e politica nell'opera di Vilfredo Pareto Firenze: Leo S. Olschki.

DONNAT, Leon (1885). La politique éxperimentale. Paris: C. Reinwald. DRUCKMAN, James N. et al. (2011). Arthur. "Experimentation in political science”. In: DRUCKMAN, James N.; GREEN, Donald P.; KUKLINSKI James H. \& LUPIA. Arthur (eds.). Cambridge handbook of experimental political science. Cambridge: Cambridge University Press.

GRAMSCI, Antonio (1984). Il nostro Marx, 1918-1919: a cura di Sergio Caprioglio. Torino: Einaudi.

GRAZIANO, Luigi (1987). "The development and institutionalization of political science in Italy". International Political Science Review/Revue internationale de science politique, v. 8, n. 1, p. 41-57.

GUYOT, Yves (1881). La science économique. Paris: C. Reinwald.

KEOHANE, Robert O.; VERBA, Sidney \& KING, Gary (1994). Designing social inquiry: scientific inference in qualitative research. Princeton: Princeton University Press.

MACHIAVELLI, Niccolo (1971). Tutte le opere. A cura di M. Martelli. Firenze: Sansoni.

MORLINO, Leonardo (1991). "La scienza politica italiana: tradizione e realtà”. Rivista Italiana di Scienza Politica, v. XXI, n. 1, p. 91-124.

MOSCA, Gaetano (1982a). Scritti politici. A cura di Giorgio Sola. Torino: Utet, volume primo.

(1982b). Scritti politici. A cura di Giorgio Sola. Torino: Utet, volume secondo.

MOSCA, Gaetano \& BOUTHOUL, Gaston (1958). História das doutrinas políticas. Rio de Janeiro: Zahar.

PALANO, Damiano (2005). Geometrie del potere: materiali per la storia della sicenza política italiana. Milano: Vita e Pensiero.

PARETO, Vilfredo (1869). Principj fondamentali della teoria della elasticità dei corpi solidi e ricerche sulla integrazione delle equazioni differenziali che ne definiscono l'equilibrio. Firenze: Pellas. 
(1919). Manuale di economia politica con una introduzione alla scienza sociale. Milano: Società Editrice Libraria,.

(1949). Corso di economia politica. Torino: Einaudi.

(1974a). I sistema socialisti: a cura di Giovanni Busino. Torino: Utet. (1974b). Scritti politici: a cura de Giovanni Busino. Torino: Utet.

(1980). Scritti sociologici minori: a cura di Giovanni Busino. Torino: Utet.

(1988). Trattato di sociologia generale: edizione critica a cura di Giovanni Busino. Torino: Utet.

PERTICONE, Giacomo (1950). "Political science in Italy”. In. Contemporry political science: a survey of methods, research and teaching. Paris: Unesco. SOLA, Giorgio (1982). “Introduzione”. In: MOSCA, Gaetano. Scritti politici: a cura di Giorgio Sola, v. 1. Torino: Utet.

(1990). "La scienza politica italiana dall'unítà al fascismo". In: GHIBAUDI, S. Rota \& BARCIA, F. (cur.). Studi politici in onore di Luigi Firpo, v. IV. Milano: Angeli. (1994). Mosca. Bari: Laterza.

\section{Resumo}

O artigo investiga os debates metodológicos existentes no processo de institucionalização a ciência política italiana, no final do século XIX e início do XX. Gaetano Mosca e Vilfredo Pareto almejavam um conhecimento científico da política que fosse construído de acordo com parâmetros inspirados nas ciências naturais. Mosca advogou fortemente em favor de um método histórico que permitiria encontrar nas instituições as forças psicológicas que garantiriam a regularidade dos fenômenos políticos. Pareto propugnou um método lógico-experimental no qual proposições abstratas (princípios) condensariam as características comuns de muitos fatos apreendidos pela experiência. Ambos, entretanto, não distinguiam de modo preciso observação, experimento e experiência. As metodologias que advogaram, por essa razão, não foram muito além das técnicas de estudo da política predominantes na época.

Palavras-chaves: história da ciência política, método experimental, Gaetano Mosca, Vilfredo Pareto.

\section{Abstract}

The article investigates the methodological debates that took place during the institutionalization process of the Italian Political Science in the late nineteenth and early twentieth centuries. Gaetano Mosca and Vilfredo Pareto aspired for a scientific knowledge 
of the policy to be built in correspondence to natural sciences practices. Mosca strongly advocated for a historical method that would find the psychological forces inside the institutions that could guarantee the regularity of the political phenomena. Pareto advocated a logical-experimental method in which abstract propositions (principles) condense the common features of many facts apprehended through experience. Both projects, however, did not distinguish precisely observation, experiment and experience. For this reason, their methodologies were not able to go beyond the hegemonic political study techniques of their time.

Keywords: history of political science, experimental method, Gaetano Mosca, Vilfredo Pareto.

Recebido em 17 de junho de 2015.

Aprovado em 4 de março de 2016. 